\title{
Anodic Oxidation of Dithiane Carboxylic Acids: A Rapid and Mild Way to Access Functionalised Orthoesters
}

\author{
Anthony D. Garcia, Matthew C. Leech, Alessia Petti, Camille Denis, Iain C. A. Goodall, Adrian P. \\ Dobbs and Kevin Lam*
}

School of Science, University of Greenwich, Chatham Maritime, Chatham, Kent, ME4 4TB (UK)
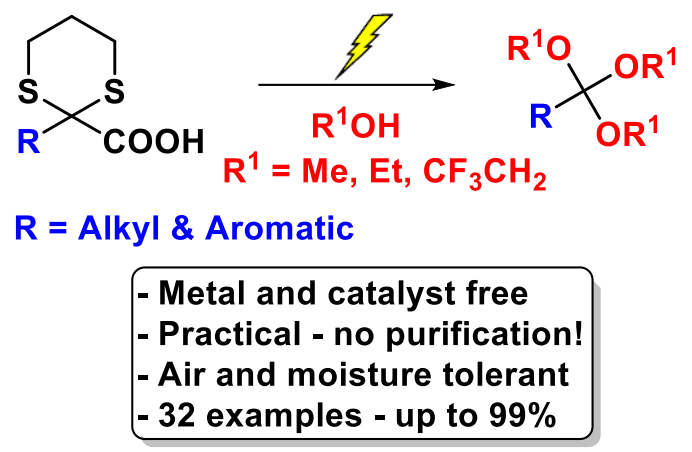

ABSTRACT: A new electrochemical methodology has been developed for the preparation of a wide variety of functionalised orthoesters under mild and green conditions from easily accessible dithiane derivatives. The new methodology also offers an unprecedented way to access tri(fluorinated) orthoesters, a class of compound that has never been studied before. This provides the community with a rapid and general method to prepare libraries of functionalised orthoesters from simple and readily available starting materials.

\section{Introduction}

Scheme 1. Common reactions using orthoesters

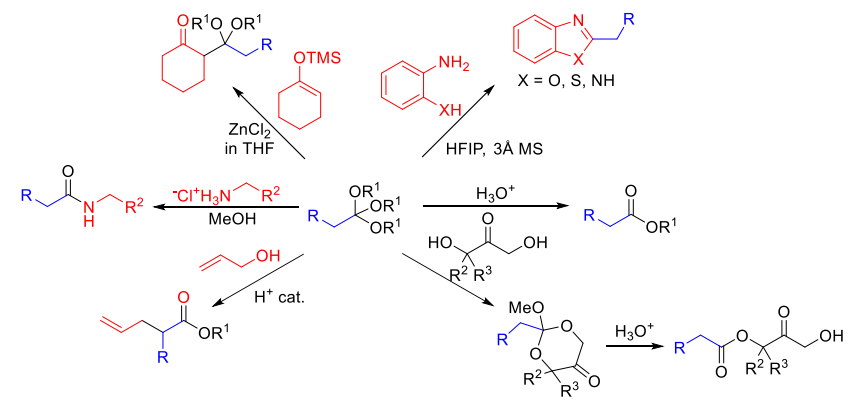

Orthoesters are highly reactive compounds that have found many applications in synthesis such as diol protecting groups, ${ }^{1}$ acylating agents, ${ }^{2}$ Claisen rearrangement reagents ${ }^{3}$ or coupling partners in heterocyclic chemistry (Scheme 1). ${ }^{4-6}$ Orthoesters have also found applications in medicinal chemistry. For instance, treatment of betamethasone, an anti-inflammatory and immunosuppressive compound, with an orthoester decreases its absorption through the skin and increases its potency. ${ }^{7} \mathrm{Re}$ cently, orthoesters have also been employed in supramolecular and material science. ${ }^{8}$ Nevertheless, the methods used to prepare them remain non-trivial, lengthy and usually require harsh conditions that significantly limit the tolerance of common functional groups. ${ }^{9}$ Therefore, unsurprisingly, only a few orthoesters are commercially available which may have impeded the development of their chemistry.

Several chemical methods have been developed to access orthoesters (Scheme 2a). ${ }^{10-12}$ Unfortunately, most of them rely on unstable precursors in addition to dangerous and toxic reagents and lead to the formation of significant amounts of inorganic salts as by-products. The Pinner synthesis is the most employed method for the preparation of orthoesters even though it is mostly restricted to aliphatic nitriles. It requires the use of gaseous $\mathrm{HCN}$ or $\mathrm{HCl}$ to prepare an imidate salt, which is then slowly decomposed in the presence of an alcohol, usually over several days, to form the desired orthoesters in modest yields. ${ }^{13,14}$ Unsurprisingly, common functional groups, such as nitriles, amides or even alkenes are incompatible with such harsh reaction conditions.

Recently, electrosynthesis has gained significant attention from the synthetic community. ${ }^{15-17}$ Electrosynthesis represents a practical, green and economically-relevant way to activate small organic molecules. While several electrosyntheses of orthoesters have been reported before (Scheme 2b), ${ }^{18-21}$ none of them provide a general route to access functionalised orthoesters, and previously reported electrosynthetic examples are generally restricted to very specific compounds. Therefore, in this article, we would like to disclose a new general, practical, versatile and scalable electrochemical methodology to access both aromatic and aliphatic orthoesters in good yields. 
Scheme 2. Common methods to prepare orthoesters.

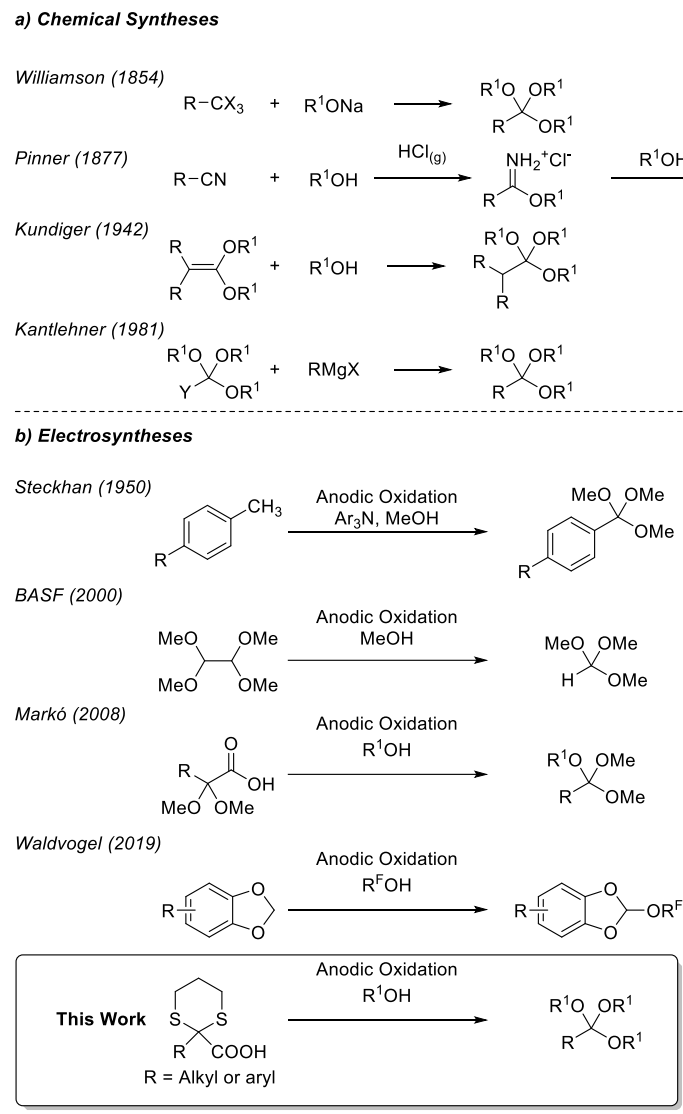

We would like to introduce dithiane carboxylic acid $\mathbf{1}$ (DTCOOH) as a nucleophilic orthoester/ester equivalent. ${ }^{22}$ The anodic oxidation of the dithiane moiety followed by a HoferMoest decarboxylation should lead to the desired orthoester. ${ }^{17,23,24}$

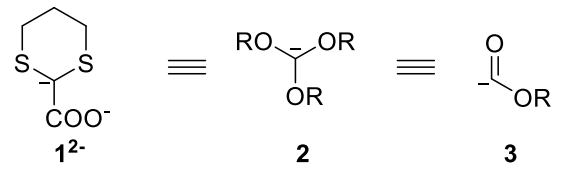

Figure 1. DTCOOH - A new orthoester and ester synthon.

\section{Results and discussion}

Dithiane carboxylic acid 1, a bench stable crystalline solid, is readily prepared, on large scale, by treating glyoxylic acid 4 with 1,3-propanedithiol in the presence of a catalytic amount of PTSA (Scheme 3). ${ }^{25}$

Scheme 3. Preparation of DTCOOH

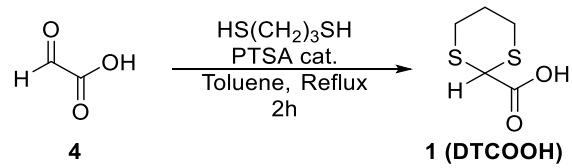

The synthesis of the alkylated electrolysis precursors $\mathbf{5}$ is simple and rapid, with high yields obtained. This can be achieved in several ways. For instance, treating DTCOOH 1 with two equivalents of $n$-BuLi leads to the formation of $\left[\mathrm{Li}^{+}\right]_{2}\left[\mathbf{1}^{2-}\right]$. The dianion can then be alkylated with a suitable electrophile (Scheme 4A). Alternatively, aldehydes 6 can be converted into their corresponding dithianes, deprotonated and then carboxylated with $\mathrm{CO}_{2}$ (Scheme 4B). Finally, alpha-keto acids can be converted directly into 5 by treatment with 1,3propandithiol (Scheme 4C).

Scheme 4. Preparation of electrolysis precusors 5.

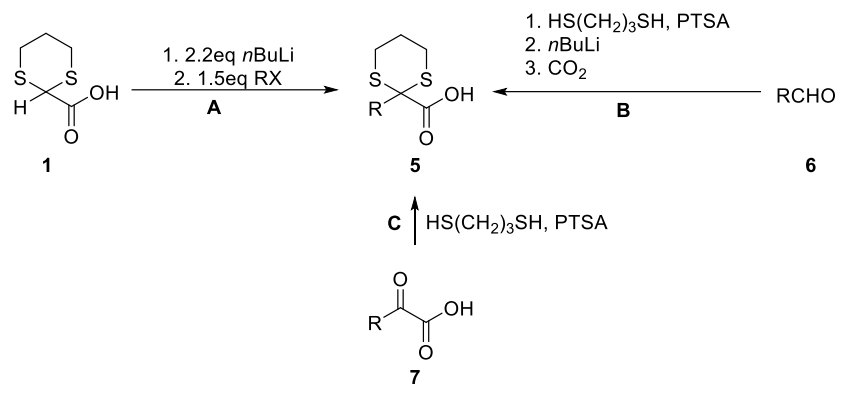

The dithiane $n$-OctDTCOOH $\mathbf{5 a}(\mathbf{5}, \mathrm{R}=n$-Oct $)$ was chosen as a model compound for the initial mechanistic and optimisation studies due to the low volatility of the corresponding orthoester. The anodic oxidation of dithianes in aqueous media has been reported before. One common general feature among the previous reports is that an important fouling of the electrodes occurs during the electrolysis. ${ }^{26}$ To solve this issue, Steckhan et al. reported the use of a triarylamminium radical-cation as an electrooxidant mediator. ${ }^{27}$ The use of a mediator allows the redox reaction to take place in the bulk of the solution rather than at the electrode surface, thus avoiding fouling. Unfortunately, in our case, the use of a mediator would only allow for an electron transfer with the easily oxidisable sulfur atoms and would leave the carboxylic acid untouched due to its high oxidation potential. $^{28}$

Cyclic voltammetric (CV) experiments performed on 5a show that the compound is oxidised at $\mathrm{E}_{\mathrm{pa}}=1.38 \mathrm{~V}$ vs $\mathrm{Fc}^{+} / \mathrm{Fc}$, a potential similar to the one reported for the oxidation of dithianes. ${ }^{27}$ The CV studies also confirmed the anodic fouling of the electrode as it can be seen from the current crossings at 0.8 and $1.15 \mathrm{~V}$ vs $\mathrm{Fc}^{+} / \mathrm{Fc}$ (See supporting information CV1).

The addition of an equivalent of collidine leads to the formation of an anion with a lower oxidation potential $\left(\mathrm{E}_{\mathrm{pa}}=1.0 \mathrm{~V}\right.$ vs $\mathrm{Fc}^{+} / \mathrm{Fc}$ ) and also completely suppresses the fouling of the electrode (See supporting information CV2). Addition of a second equivalent shows that only traces of acid remain while adding 5 equivalents of base converts the carboxylic acid entirely into its carboxylate.

Based on our previous experience with the anodic decarboxylation of carboxylic acids, we decided to investigate the use of "Kolbe-type" anodic decarboxylation conditions. ${ }^{29-31}$ The dithiane carboxylic derivative $\mathbf{5}$ was treated with a base in order to generate the corresponding carboxylate $5^{-}$. The neutralisation of the carboxylic acid serves three purposes: it makes the medium conductive, it favours the adsorption of the negatively charged carboxylate onto the positively charged anode and it avoids fouling of the electrodes.

We then explored the preparative anodic oxidation of 5a. A full optimisation table can be found in the supporting information, while salient results are summarised in Table 1. At the end of the electrolysis, the orthoester can easily be isolated by a rapid extraction of the electrolysis solution using hexane and either an $\mathrm{NaOH}$ or $\mathrm{NaHCO}_{3}$ aqueous solution, followed by the evaporation of the hexane. As shown by GC-MS analysis, 1,2dithiolane 9 is the main by-product produced during the electrolysis. The disulfide is volatile enough to be removed under 
reduced pressure leaving the orthoester sufficiently pure to be used without further purification in the next reaction step.

Due to their inherent instability, NMR yields have been measured for the orthoesters using dibromomethane as an internal standard.

Table 1. Optimisation parameters<smiles>O=C(O)C1(Cl)SCCCS1</smiles>

$5 a$
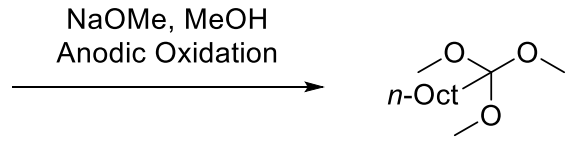

$8 \mathbf{a}$

\begin{tabular}{lllllll} 
Entry & $\begin{array}{l}\text { Conc. } \\
\mathbf{5 a} \\
/ \mathrm{mM}\end{array}$ & $\begin{array}{l}\text { Base } \\
\text { /eq }\end{array}$ & $\begin{array}{l}\text { Current } \\
\text { density } \\
/ \mathrm{mA} \cdot \mathrm{cm}^{-2}\end{array}$ & $\begin{array}{l}\text { Fara- } \\
\text { days } \\
/ \text { F.mol }\end{array}$ & $\begin{array}{l}\text { Elec- } \\
\text { trode } \\
(+/-)\end{array}$ & $\begin{array}{l}\text { Yield } \\
\mathbf{8 a}\end{array}$ \\
\hline $1^{\mathrm{a}}$ & 36 & 1 & 36 & 15 & $\mathrm{Pt} / \mathrm{Ni}$ & 21 \\
$2^{\mathrm{a}}$ & 36 & 1 & 18 & 15 & $\mathrm{Pt} / \mathrm{Ni}$ & 20 \\
$3^{\mathrm{b}}$ & 36 & 1 & 36 & 15 & $\mathrm{C} / \mathrm{C}$ & 28 \\
$4^{\mathrm{b}}$ & 18 & 1 & 36 & 15 & $\mathrm{C} / \mathrm{C}$ & 42 \\
$5^{\mathrm{b}}$ & 18 & 1 & 36 & 30 & $\mathrm{C} / \mathrm{C}$ & 58 \\
$6^{\mathrm{b}}$ & 9 & 2 & 36 & 30 & $\mathrm{C} / \mathrm{C}$ & 99 \\
$7^{\mathrm{b}}$ & 181 & 2 & 36 & 30 & $\mathrm{C} / \mathrm{C}$ & 76
\end{tabular}

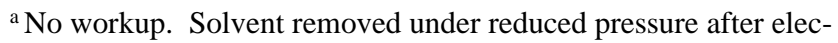
trolysis.

${ }^{\mathrm{b}}$ Reaction mixture quenched with aqueous $\mathrm{NaHCO}_{3}$, and subsequently extracted with hexanes.

The concentration of $\mathbf{5 a}$ was shown to be a crucial parameter. Salient results are sumirised in Table 1. On a small scale $(\approx 0.1 \mathrm{mmol})$ (Entries $1-7)$, diluted conditions $(9 \mathrm{mM})$ gave the best results (Entry 7). Surprisingly, when $1.81 \mathrm{mmol}$ of $\mathbf{5 a}$ were electrolysed in $10 \mathrm{~mL}$ of methanol $(181 \mathrm{mM})$, only a minor drop in yield was observed (Entry 8).

As expected, carbon graphite electrodes (Entry 3) have shown to be superior to platinum electrodes at achieving a multi-electron transfer (Entry 2). Presumably this is because the substrate is better adsorbed on carbon than on a metallic surface. The current density was shown to have very little impact on the reaction as long as it is greater than or equal to $18 \mathrm{~mA} . \mathrm{cm}^{-2}(\mathrm{En}-$ tries 1, 2, 5 and 6).

No significant difference in yield was observed upon exchange of $\mathrm{NaOMe}$ for ammonia as base, however, a notable decrease was observed upon use of $t$-BuOK, presumably due to its limited solubility in methanol (See supporting information Table 1). Although, in theory, a catalytic amount of base should be sufficient since methoxide ions are produced continuously during the electrode by reduction of the methanol at the cathode, we found that using two equivalents helps to reduce the impedance of the system and minimise the Joule effect.

Similar to what we have observed during our previous investigations, oxygen and moisture have little to no effect on the electrolysis. $^{32,33}$

Scheme 5. Possible Mechanism

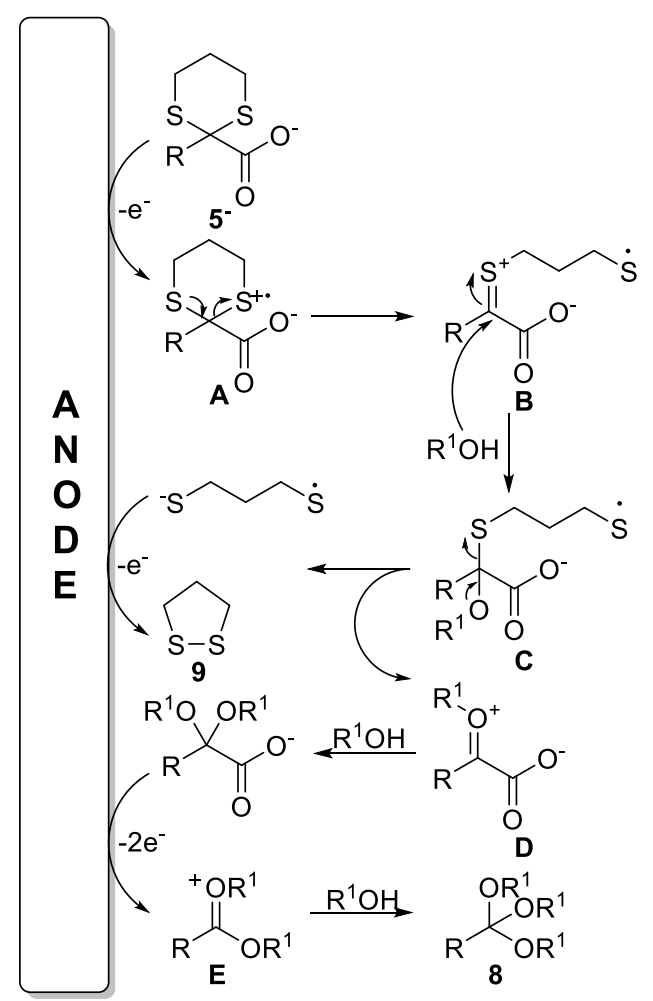

Scheme 5 shows a possible mechanism. The reaction starts with the oxidation of one of the two sulfur centres of $5^{-}$since their oxidation potential is much lower than that of a carboxylate. The dithiane then opens to form the corresponding thionium B. This intermediate is then attacked by the solvent to form the mixed $S, O$ acetal $\mathbf{C}$ which quickly decomposes into the oxonium $\mathbf{D}$ by releasing a disulfide, which is oxidised into the corresponding dithiolane 9. Alternatively, C's sulfur moiety can be oxidised and release the oxonium $\mathbf{D}$ as well as a 1,3propandithiyl radical that cyclises into 9 . Finally, another molecule of solvent adds onto the oxonium $\mathbf{D}$ to form a carboxylic acetal that decarboxylates to form the desired orthoester $\mathbf{8}$ following a classical Kolbe/Hofer-Moest decarboxylation. Alternatively, a reviewer made the interesting suggestion that the intermediate A could decarboxylate rapidly by undergoing an intramolecular electron transfer from the carboxylate to the sulfur radical-cation (See supporting information - Figure M1 for an alternative mechanism). ${ }^{24}$ 


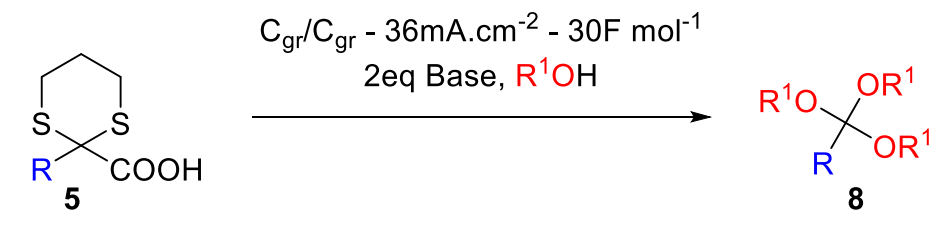

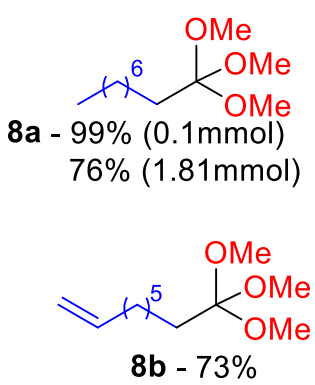

$\mathrm{Cl}_{\mathrm{OMe}}^{\mathrm{OMe}}$

8c $-92 \%$<smiles>COC(CCCCBr)(OC)OC</smiles>

8d - $88 \%$

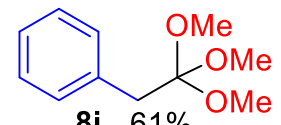

$8 \mathbf{i}-61 \%$ OMe

NC<smiles>COC(Cc1ccc(I)cc1)(OC)OC</smiles>

8j - $42 \%$

$\mathrm{Cl}$<smiles>COC(Cc1ccc(C)cc1)(OC)OC</smiles>

8k - $47 \%$<smiles>COC(Cc1ccc(Br)cc1)(OC)OC</smiles>

$81-44 \%$<smiles>COC(Cc1ccc(F)cc1)(OC)OC</smiles>

$8 q-54 \%$

$8 r-52 \%$<smiles>COC(CC1CCOCC1)(OC)OC</smiles>

$8 y-59 \%$ (15F)<smiles>COC(OC)(OC)c1ccccc1</smiles>

$8 z-98 \%, 85 \% c$<smiles>COC(Cc1cccc(Br)c1)(OC)OC</smiles>

$8 s-58 \%$<smiles>CCOC(OCC)(OCC)c1ccccc1</smiles><smiles>[R20][R6](=O)(O)COC(OCC(F)(F)F)(OCC(F)(F)F)c1ccccc1</smiles>

$$
\mathrm{X}=\mathrm{Cl} 8 \mathrm{t}-97 \%
$$

$\mathrm{X}=\mathrm{Br} \mathbf{8 z 7}-82 \%$<smiles>COC(Cc1ccc(C(F)(F)F)cc1)(OC)OC</smiles>

$8 m-44 \%$<smiles>COC(Cc1ccc(C(C)(C)C)cc1)(OC)OC</smiles>

$8 u-75 \%$<smiles>COc1cccc(CC(OC)(OC)OC)c1</smiles>

$8 v-25 \%$<smiles>OC(OCC(F)(F)F)(OCC(F)(F)F)C12CC3CC(CC(C3)C1)C2</smiles>

$8 w-72 \%$

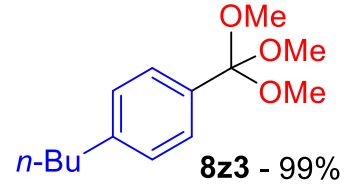

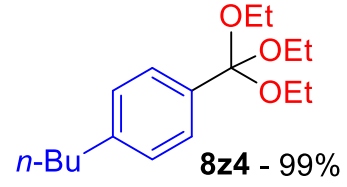

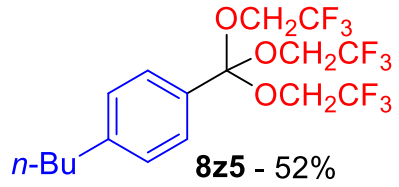

$\mathbf{8 g}-75 \%$<smiles>C#CCCCCC(OC)(OC)OC</smiles>

8 h $-53 \%$<smiles>COC(CCCCC#N)(OC)OC</smiles>

$8 p-48 \%$<smiles>COCCCCC(OC)(OC)OC</smiles>

$8 x-63 \%$<smiles>COC(CCC(OC)(OC)OC)(OC)OC</smiles>

$8 \mathbf{8 6}$ - 75\% (60F)

Figure 2 Scope of the electrochemical orthoesterification. ${ }^{a}$ Typical procedure: in a $10 \mathrm{~mL}$ Electrasyn cell equipped with two graphite electrodes, $0.1 \mathrm{mmol}$ (or $1.81 \mathrm{mmol}$ ) of 5 were dissolved in $10 \mathrm{~mL}$ of $\mathrm{MeOH}$ and 2eq. of $\mathrm{NaOMe}$ (for OMe orthoesters) or $t$-BuOK (for $\mathrm{OEt}$ and $\mathrm{OCH}_{2} \mathrm{CF}_{3}$ orthoesters) were. The solution was electrolysed for $30 \mathrm{~F} . \mathrm{mol}^{-1}$ or $15 \mathrm{~F} . \mathrm{mol}^{-1}$ with a current density of $36 \mathrm{~mA} . \mathrm{cm}$ ${ }^{2} .{ }^{b}$ Due to the instability of the orthoesters, the yields were measured by NMR using dibromomethane as a reference. ${ }^{\mathrm{c}}$ From the corresponding dibenzyl thioacetal. 
With these conditions in hand, we explored the scope and limitations of the anodic oxidation of dithiane carboxylic acid derivatives.

A large number of functional groups, such as alkenes, alkynes, silyl ethers, Boc carbamates or nitriles, are not tolerated by the classic Pinner due to the highly acidic conditions used. In addition, the Pinner reaction is known to be unsuccessful for the preparation of aromatic orthoesters. ${ }^{14}$ As it can be seen from Figure 2, our methodology is compatible with both aliphatic and aromatic substituents. The anodic oxidation of $\mathbf{5}$ tolerates a wide variety of functional groups such as: alkenes $(\mathbf{8 b})$, alkynes $(\mathbf{8 h})$, silyl groups $(\mathbf{8 e})$, halides $(\mathbf{8 b}, \mathbf{c}, \mathbf{d}, \mathbf{k}, \mathbf{l}, \mathbf{r}, \mathbf{s})$, fluorinated groups $(\mathbf{8 m}, \mathbf{q}, \mathbf{t})$, nitriles $(\mathbf{8 j}, \mathbf{p})$, ethers $(\mathbf{8 x}, \mathbf{y}, \mathbf{v})$ and amides $(\mathbf{8 n})$. For the cyclic ether $\mathbf{8 y}$ and amide $\mathbf{8 n}$ the electrolyses were only undertaken for $15 \mathrm{~F} . \mathrm{mol}^{-1}$ since prolonged electrolysis of these compounds led to the formation of the Shono-type oxidation product (alpha-methoxylation of the ether or amide) ${ }^{34}$ Replacing the dithiane with the less expensive dibenzyl thioacetal led to a slight decrease in the yield of the orthoester $(\mathbf{8 z})$ and the side product, dibenzyldisulfide, was difficult to remove completely due to its low volatility.

Using ethanol or trifluoroethanol as solvents for the electrolysis allowed us to easily access a series of triethyl and trifluoroethyl orthoesters. Reports of tri(ethyl)orthoesters are even scarcer in the literature than those about their trimethyl analogues. Moreover, there are only two known tri(trifluoroethyl) orthoesters reported as by-products of a reaction and with no further study on them. In our hands, we found that tri(trifluoroethyl) orthoesters were highly reactive and hydrolyse extremely rapidly compared to their non-fluorinated analogues.

Finally, we engaged the electrochemically synthesised orthoesters in some of the possible subsequent reactions to demonstrate their synthetic utility (Scheme 6). The anodically prepared orthoesters were successfully used for the synthesis of heterocyclic compounds using metal and Lewis acid-free conditions (See supporting information for examples) ${ }^{35}$ as well as for a Pd-catalysed Suzuki cross-coupling.

Scheme 6. Synthetic applications of anodically prepared orthoesters,

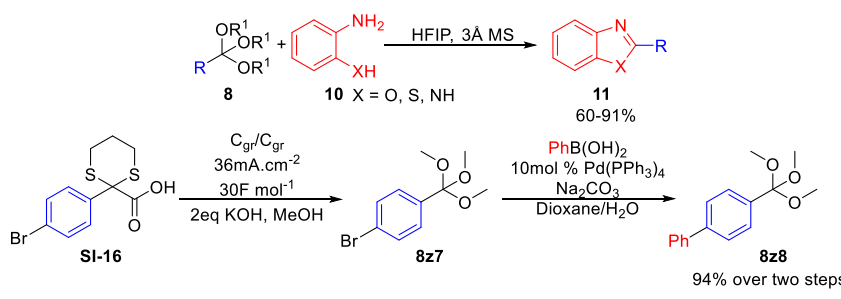

\section{Conclusion}

In conclusion, we have demonstrated that dithiane carboxylic acids are versatile precursors of orthoesters. The starting materials are easily prepared in high yields in a few steps from readily available materials. The new electrosynthetic methodology is practical, mild, green, economically relevant and tolerates a wide variety of functional groups that are not usually compatible with the classic methods to prepare orthoesters. Finally, tri(trifluoroethyl) orthoesters are easily prepared using this method, which would ease the study of this class of compounds.

\section{ASSOCIATED CONTENT}

(The Supporting Information is available free of charge at XXXX. Synthetic procedures, spectral data, compound characterization.

\section{AUTHOR INFORMATION}

\section{Corresponding Author}

*k.lam@greenwich.ac.uk

Funding Sources

EPSRC Grant EP/S017097/1

European Union's Horizon 2020 - Marie Skłodowska -Curie

Grant 801604

Notes

Any additional relevant notes should be placed here.

\section{ACKNOWLEDGMENT}

The authors are grateful to the Engineering and Physical Sciences Research Council (Grant EP/S017097/1 to KL and MCL) for their financial support, the University of Greenwich (Vice Chancellor's $\mathrm{PhD}$ Scholarship to AP and Fellowship to CD), the University Alliance "Applied Biosciences for Health" Marie Skłodowska -Curie Grant 801604 (PhD scholarship to AG), and IKA for their material support (to KL).

\section{REFERENCES}

(1) Wipf, P.; Tsuchimoto, T.; Takahashi, H. Synthetic Applications of Ortho Esters. Pure Appl. Chem. 1999, 71 (3), 415-421. https://doi.org/10.1351/pac199971030415.

(2) Saba, S.; Ciaccio, J. A. Reaction of Orthoesters with Amine Hydrochlorides: An Introductory Organic Lab Experiment Combining Synthesis, Spectral Analysis, and Mechanistic Discovery. J. Chem. Educ. 2016, 93 (5), 945-948. https://doi.org/10.1021/acs.jchemed.5b00782.

(3) Montero, A.; Mann, E.; Herradón, B. Preparation of Sugar Amino Acids by Claisen-Johnson Rearrangement: Synthesis and Incorporation into Enkephalin Analogues. European J. Org. Chem. 2004, No. 14, 3063-3073. https://doi.org/10.1002/ejoc.200400166.

(4) Bastug, G.; Eviolitte, C.; Markó, I. E. Functionalized Orthoesters as Powerful Building Blocks for the Efficient Preparation of Heteroaromatic Bicycles. Org. Lett. 2012, 14 (13), 3502-3505. https://doi.org/10.1021/ol301472a.

(5) Zieliński, W.; Kudelko, A.; Czardybon, W. The Synthesis of 4Acylamino-1,2,4-Triazole Derivatives in the Reaction of $\alpha$ Hydroxyacid Hydrazides and Orthoesters. J. Heterocycl. Chem. 2005, 42 (7), 1393-1397. https://doi.org/10.1002/jhet.5570420720.

(6) Maulide, N.; Markó, I. E. Stereoselective Synthesis of Bicyclic Lactones by Annelation with Functionalised Orthoesters. Chem. Commun. 2006, No. 11, 1200-1202. https://doi.org/10.1039/b600677a.

(7) Ercoli, A.; Gardi, R. 17alpha, 21-Substituted Methylenedioxy Steroids and Methods Therefor. US Pat. 3147249, 1964.

(8) Brachvogel, R. C.; Von Delius, M. Orthoester Exchange: A Tripodal Tool for Dynamic Covalent and Systems Chemistry. Chem. Sci. 2015, $6 \quad$ (2), 1399-1403. https://doi.org/10.1039/c4sc03528c.

(9) Pavlova, L. A.; Davidovich, Y. A.; Rogozhin, S. V. Alkyl Orthoesters and Their Applications in Organic Synthesis. Russ. Chem. Rev. 1986, 55 (11), 1026-1041. https://doi.org/10.1070/rc1986v055n11abeh003238.

(10) Williamson, A. W.; Kay, G. Ueber Einige Neue Abkömmlinge Des Chloroforms. Justus Liebigs Ann. Chem. 1854, 92 (3), 346348. https://doi.org/10.1002/jlac.18540920320.

(11) McElvain, S. M.; Kundiger, D. Ketene Acetals. VII. The Reaction of Ketene Diethylacetal with Various Halogen Compounds and Acids. J. Am. Chem. Soc. 1942, 64 (2), 254-259. https://doi.org/10.1021/ja01254a015.

Kantlehner, W.; Maier, T.; Kapassakalidis, J. J. Ein Neues Ergiebiges Verfahren Zur Herstellung von TrialkylOrthobenzoaten Und Trialkyl-Orthophenylpropynoaten. 
Synthesis (Stuttg). 1981, $1981 \quad$ (05), 380-381. https://doi.org/10.1055/s-1981-29458.

(13) Pinner, A. Ueber Die Umwandlung Der Nitrile in Imide. Berichte der Dtsch. Chem. Gesellschaft 1883, 16 (2), 1643-1655. https://doi.org/10.1002/cber.18830160235.

(14) Noè, M.; Perosa, A.; Selva, M. A Flexible Pinner Preparation of Orthoesters: The Model Case of Trimethylorthobenzoate. Green Chem. 2013, $15 \quad$ (8), 2252-2260. https://doi.org/10.1039/c3gc40774h.

(15) Yan, M.; Kawamata, Y.; Baran, P. S. Synthetic Organic Electrochemical Methods since 2000: On the Verge of a Renaissance. Chemical Reviews. American Chemical Society November 8, 2017, pp 13230-13319. https://doi.org/10.1021/acs.chemrev.7b00397.

(16) Möhle, S.; Zirbes, M.; Rodrigo, E.; Gieshoff, T.; Wiebe, A.; Waldvogel, S. R. Modern Electrochemical Aspects for the Synthesis of Value-Added Organic Products. Angewandte Chemie - International Edition. Wiley-VCH Verlag May 22, 2018, pp 6018-6041. https://doi.org/10.1002/anie.201712732.

(17) Leech, M. C.; Lam, K. Electrosynthesis Using Carboxylic Acid Derivatives: New Tricks for Old Reactions. Acc. Chem. Res. 2020 , acs.accounts.9b00586 https://doi.org/10.1021/acs.accounts.9b00586.

(18) Brinkhaus, K. H. G.; Steckhan, E.; Degner, D. Indirect Electrochemical Side-Chain Oxidation of Alkyl Aromatic Compounds - Selective Synthesis of Methyl Benzoates or OrthoBenzoic Acid Trimethylesters. Tetrahedron 1986, 42 (2), 553560. https://doi.org/10.1016/S0040-4020(01)87454-8.

(19) Fischer, A.; Pütter, H. METHOD FOR PRODUCING ORTHOCARBONIC ACID TRIALKYL ESTERS. EP1362022A1, September 5, 2007.

(20) Lebreux, F.; Buzzo, F.; Markó, I. E. Studies in the Oxidation of Carboxylic Acids: New Twists for an Old Reaction. Synthesis of Various Cyclic Systems and Substituted Orthoesters. In ECS Transactions; 2008; $\quad$ Vol. $13, \quad$ pp 1-10. https://doi.org/10.1149/1.3013282.

(21) Röckl, J. L.; Hauck, A. V.; Schollmeyer, D.; Waldvogel, S. R. Electrochemical Synthesis of Fluorinated Orthoesters from 1,3Benzodioxoles. ChemistryOpen 2019, 8 (9), 1167-1171. https://doi.org/10.1002/open.201900127.

(22) Garcia, A.; Leech, M.; Petti, A.; Denis, C.; Goodall, I. C. A.; Dobbs, A.; Lam, K. Anodic Oxidation of Dithiane Carboxylic Acids: A Rapid, Mild and Practical Way to Access Functionalised Orthoesters, 2020, ChemRxiv. Preprint. https://doi.org/10.26434/chemrxiv.12137550.v1 (accessed April $23,2020)$

(23) Xiang, J.; Shang, M.; Kawamata, Y.; Lundberg, H.; Reisberg, S. H.; Chen, M.; Mykhailiuk, P.; Beutner, G.; Collins, M. R.; Davies, A.; Del Bel, M.; Gallego, G. M.; Spangler, J. E.; Starr, J.; Yang, S.; Blackmond, D. G.; Baran, P. S. Hindered Dialkyl Ether Synthesis with Electrogenerated Carbocations. Nature. Nature Publishing Group September 19, 2019, pp 398-402. https://doi.org/10.1038/s41586-019-1539-y.

(24) Perkins, R. J.; Xu, H.-C.; Campbell, J. M.; Moeller, K. D. Anodic Coupling of Carboxylic Acids to Electron-Rich Double Bonds: A
Surprising Non-Kolbe Pathway to Lactones. Beilstein J. Org. Chem. 2013, 9, 1630-1636. https://doi.org/10.3762/bjoc.9.186.

(25) Bates, G. S.; Ramaswamy, S. Dianions of Glyoxylic Acid Thioketals: Conventent $\alpha$-Keto Acid Equivalents. Can. J. Chem. 1980, 58 (7), 716-722. https://doi.org/10.1139/v80-110.

(26) Porter, Q. N.; Utley, J. H. P.; Machion, P. D.; Pardini, V. L.; Schumacher, P. R.; Viertier, H. Electro-Organic Reactions. Part 24. Preparative and Mechanistic Aspects of the Anodic Oxidation of Dithioacetals and 1,3-Dithianes. J. Chem. Soc. Perkin Trans. 1 1984, 973-979. https://doi.org/10.1002/chin.198434075.

(27) Platen, M.; Steckhan, E. Mild and Effective Removal of Dithioketal Protecting Groups by Triarylamine Cation Radicals as Homogeneous Electron Transfer Agents. Chem. Ber. 1984, 117 (5), 1679-1694. https://doi.org/10.1002/cber.19841170505.

(28) Schäfer, H. J. Recent Contributions of Kolbe Electrolysis to Organic Synthesis. Top. Curr. Chem. 1990, 152 (4), 91-151. https://doi.org/10.1007/BFb0034362.

(29) van Melis, C. G. W.; Penny, M. R.; Garcia, A. D.; Petti, A.; Dobbs, A. P.; Hilton, S. T.; Lam, K. Supporting-Electrolyte-Free Electrochemical Methoxymethylation of Alcohols Using a 3DPrinted Electrosynthesis Continuous Flow Cell System. ChemElectroChem 2019, 6 (16), 4144-4148. https://doi.org/10.1002/celc.201900815.

(30) Luo, X.; Ma, X.; Lebreux, F.; Markó, I. E.; Lam, K. Electrochemical Methoxymethylation of Alcohols - a New, Green and Safe Approach for the Preparation of MOM Ethers and Other Acetals. Chem. Commun. 2018, 54, 9969-9972. https://doi.org/10.1039/C8CC05843A.

(31) Ma, X.; Dewez, D. F.; Du, L.; Luo, X.; István, M. E.; Lam, K. Synthesis of Diketones, Ketoesters, and Tetraketones by Electrochemical Oxidative Decarboxylation of Malonic Acid Derivatives: Application to the Synthesis of Cis-Jasmone. J. Org. Chem. 2018, 83, 12044-12055. https://doi.org/10.1021/acs.joc.8b01994.

(32) Petti, A.; Leech, M. C.; Garcia, A. D.; Goodall, I. C. A.; Dobbs, A. P.; Lam, K. Economical, Green, and Safe Route Towards Substituted Lactones by Anodic Generation of Oxycarbonyl Radicals. Angew. Chemie Int. Ed. 2019, 58 (45), 16115-16118. https://doi.org/10.1002/anie.201909922.

(33) Hayrapetyan, D.; Shkepu, V.; Seilkhanov, O. T.; Zhanabil, Z.; Lam, K. Electrochemical Synthesis of Phthalides via Anodic Activation of Aromatic Carboxylic Acids. Chem. Commun. 2017, 53 (60), 8451-8454. https://doi.org/10.1039/C7CC03669H.

(34) Shono, T.; Hamaguchi, H.; Matsumura, Y. Electroorganic Chemistry. XX. Anodic Oxidation of Carbamates. J. Am. Chem. Soc. $\quad 1975, \quad 97 \quad$ (15), 4264-4268. https://doi.org/10.1021/ja00848a020.

(35) Khaksar, S.; Heydari, A.; Tajbakhsh, M.; Vahdat, S. M. Lewis Acid Catalyst Free Synthesis of Benzimidazoles and Formamidines in 1,1,1,3,3,3-Hexafluoro-2-Propanol. J. Fluor. Chem. 2010, $131 \quad$ (12), 1377-1381 https://doi.org/10.1016/j.jfluchem.2010.10.002. 
